\title{
Revisit the provenance and weathering intensity registerted in the Red River estuarine sediments
}

\author{
ZHIFEI DuAN ${ }^{1}$, ChaO Li $^{1}$, YulONG GUO ${ }^{1}$, NiCHOLAS NG \\ Chia WeI ${ }^{1}$, ShOUYe YANG ${ }^{1}$, XIAOYONG DuAN ${ }^{2}$, PING \\ YIN $^{2}$, BUI VAN VUONG ${ }^{3}$ \\ ${ }^{1}$ State Key Laboratory of Marine Geology, Tongji \\ University, Shanghai 200092, China \\ ${ }^{2}$ Qingdao Institute of Marine Geology, China Geological \\ Survey, Qingdao 266071, China \\ ${ }^{3}$ Institute of Marine Environment and Resources, Vietnam \\ Academy of Science and Technology, HaiPhong 18000, \\ VietNam
}

The Red River delivers $1.3 \times 10^{8} \mathrm{t} / \mathrm{a}$ materials to the South China Sea (SCS), and plays an important role in the sediment source-to-sink transport processes in the SCS. Despite previous work, the geochemical characteristics of the Red River sediment need further investigation for the better understanding of sediment sources and weathering processes in the north SCS, and especially, for tracing the influence of Red River on the north and even the south SCS.

We present the elemental and $\mathrm{Sr}-\mathrm{Nd}$ isotopic composition of 27 sediment samples collected from the Red River estuary. The estuarine sediments are characterized by high La and low Sc concentrations, similar with those in Beibu Gulf (Gulf of Tonkin). The values of chemical index of alteration (CIA) are 75 82, similar to those of Mekong River but lower than the Pearl River. The $\varepsilon N d$ value of the Red River estuarine sediments ranges from -11.2 to -12.5 , less variable than previous investigation of the catchment sediments, therefore providing a more robust constraint on discriminating the sediment source in the SCS. The ${ }^{87} \mathrm{Sr} /{ }^{86} \mathrm{Sr}$ shows a linear relationship with $\mathrm{Rb} / \mathrm{Sr}$ and $\mathrm{K}_{2} \mathrm{O} /\left(\mathrm{Na}_{2} \mathrm{O}+\mathrm{CaO}\right)$, which confirms that the ${ }^{87} \mathrm{Sr} /{ }^{86} \mathrm{Sr}$ ratio in the Red River sediment is primarily controlled by the degree of plagioclase weathering, and not determined by the mixing of different tributaries. The effect of quartz dilution results in the deviation of bulk sediment chemistry from the first-cycle weathering trend, which has to be carefully considered in the study of catchment weathering.

This work presents a more systematic and comprehensive geochemical database for the Red River estuarine sediments, which offers a thorough investigation on sediment provenance and weathering characteristics in the Red River catchment, and provides deep insights to the study of sediment provenance and paleoenvironmental changes in the SCS. 